\title{
Handicapped infants: medical ethics and the law
}

\author{
D D Raphael
}

\section{Author's abstract}

The main purpose of this paper (1) is to draw attention to a gap between the principles of Common Law and the principles accepted by many leading medical practitioners on the ethics of allowing severely handicapped infants to die. The Common Law principles are shown in Court of Appeal judgements on two cases. The contrasting principles of many paediatricians were illustrated at the trial of Dr Leonard Arthur. The paper suggests that the gap could be closed by statutory guidance on general principles. It also argues that utilitarian concepts misrepresent the ethical issues of medical dilemmas like this one.

The problems of medical ethics have come to the forefront of public attention in recent decades because the advance of medical science has opened up strikingly new possibilities for medical practice. In the past, the discovery of a new drug or the improvement of a surgical technique increased the capacity of doctors to cure or ward off disease, but the difference which this made was a difference of degree, hardly great enough to produce a new kind of moral dilemma. When the average span of life was sixty-five, it seemed pure gain to be able to increase it to seventy. When a fair percentage of normal babies died in childbirth, it was pure gain for improved obstetrics to render such deaths exceptional. But there is a qualitative change in the ethical situation when medical advance can preserve life for people suffering from senile dementia or for newly-born babies suffering from spina bifida or severe brain defects. It is not all pure gain now. A veterinary surgeon dealing with non-human animals would have no hesitation in 'putting down' old or newly-born creatures that were so far removed from a state of normal good health. Our ethical tradition is founded on the principle that human life is sacred; but when the life of a human being becomes (as people say exaggeratedly) 'the life of a vegetable', should it still be held sacred?

It is the possibility of actual choice between life and death that gives rise to the most agonising perplexity.

\section{Key words}

Law and medical ethics; severely handicapped infants; best interests; sanctity of human life.
There are other problems that have widespread serious $\vec{A}$ consequences but are less critical in their immediate impact upon moral choice. The dilemma of choosing ir between life and death can arise both in respect of the $\frac{}{5}$ newly born and in respect of the terminally ill. $\vec{T}$ Scientific advance has made it possible to preserve the lives of severely defective babies who in the past would $\stackrel{\frac{a}{S}}{\zeta}$ necessarily have died, after a very short period, in the course of nature. The new possibility brought with it a $\varrho_{\infty}$ genuinely new problem: should doctors follow the principle of preserving human life whenever they can, or should they refrain from using their new power in cases where the quality of life, extracted 'unnaturally', $\frac{\partial}{0}$ will be far below the normal? Scientific advance has also made it possible to prolong the lives of many $\stackrel{\varnothing}{\varnothing}$ people suffering from terminal illness. Here too the $\overrightarrow{\vec{P}}$

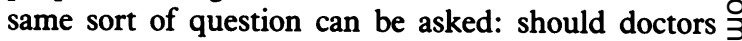
preserve human life whenever they can, or should they refrain from special efforts to 'go against nature' when the quality of the extra period of life for the patient is, by normal human standards, not worth living?

The dilemma is more acute in the first type of case than in the second. The most important reason for this is that a terminally ill patient may be able and ready to declare his or her choice on the matter, and that should clearly count for more than the opinion of relatives or, 은 often, of doctors. When the patient is a newly born $\rightarrow$ baby, however, the choice has to be made by others, a choice which is all the more poignant because of the $N$ helplessness and the stultified potential of the child. This brings me to a second reason why the dilemma is more acute in such a case than in dealing with terminal $\mathrm{\omega}$ illness. Most of the people who are terminally ill have had a fair span of life; the little extra that exceptional 6 measures can procure is like a drop in a pool. That does not remove the force of the obligation felt by a doctor : to preserve human life whenever he can, or felt by a relative to retain the presence of a dear one. It does, however, put these feelings into perspective.

I propose to concentrate on the first type of case, that $\stackrel{\mathbb{Q}}{\Omega}$ of the severely defective baby, both because the moral dilemma here is so much more acute and because it has 8 twice been the subject of court proceedings in England. In July 1980 a baby boy, John Pearson, was born suffering from Down's syndrome. At the time the condition appeared to be a straightforward case of the 
syndrome with no complications, though autopsy after the baby's death showed that this was not the case. When the mother learned, at the baby's birth, that it had Down's syndrome, she was heard to say to her husband, 'I don't want it'. Her husband presumably shared or accepted her attitude, and the paediatrician in charge, Dr Leonard Arthur, recorded a note: 'Parents do not wish baby to survive. Nursing care only'. 'Nursing care' was understood to include giving the baby water but no food. The doctor also prescribed the use of a drug to alleviate distress. The baby died after sixty-nine hours. Dr Arthur was in due course prosecuted on a criminal charge of murder. Soon after the trial began, that charge was withdrawn on the judge's direction and the prosecution substituted a charge of attempted murder. Dr Arthur was eventually acquitted.

To a layman, even if he thinks that Dr Arthur acted wrongly, the charges of murder and attempted murder seem bizarre; but some of the evidence shows why the prosecution adopted that course of action. In the first place, the particular drug prescribed by $\mathrm{Dr}$ Arthur is a potent one and its use is not recommended for infants. Moreover, the amount found in the child's blood and liver was, according to an expert witness, far beyond the level used for therapeutic purposes and substantially beyond the toxic level. Secondly, the deliberate withholding of food from a newly-born infant can be construed as causing death by starvation - though that suggestion loses force in this particular instance because the baby's weight was no less at the time of death than at birth.

The law concerning murder in fact lays severe constraints on the discretion of doctors. Professor Glanville Williams, in a letter to The Times of 13 August 1981 (this was before the trial of Dr Arthur actually took place), stated the legal position as follows:

'The general principle is that those who have the care of an infant must take reasonable steps to save its life if possible. . . . But one who deliberately omits to save a life that he is under a legal duty to save is guilty of murder, unless the law provides some defence.'

On the other hand, after the trial was over, Professor J K Mason, Professor of Forensic Medicine at Edinburgh, wrote in a letter to The Times of 7 November 1981:

'A conviction for murder or attempted murder surely implies some evil intent and this is an allegation which nobody could conceivably hold against Dr Arthur; on this count alone the verdict can never have been in doubt. . . .

'There can be little doubt, however, that neglect of care leading to the death of someone to whom one has a duty of care would, in certain circumstances, come within the compass of culpable homicide. What was needed, and what could have been decided in a trial for manslaughter, was an indication whether a doctor acting in good faith, as was Dr Arthur, is covered legally by what is effectively the doctrine of necessity.'

The pathologist who carried out a post-mortem examination attested that the baby had died from bronchial pneumonia and his opinion was that this was caused by the drug. Another pathologist, however, appearing for the defence, said that he had found in the baby abnormalities additional to Down's syndrome, including abnormality of the lungs, and that these abnormalities might have produced the pneumonia. Since on that account there could be no proof that the drug had caused the death, the charge of murder was dropped and replaced by one of attempted murder. The defence maintained that Dr Arthur's intention in prescribing the drug was purely to alleviate distress. As Professor Mason wrote in his letter, on this count of intention the verdict can never have been in doubt. Even if, as Professor Glanville Williams says, a deliberate omission to save life, when there is a duty to save it, can be murder, we could hardly imagine a present-day jury returning such a verdict in a case like this one.

The verdict would not have been so obvious, however, on a lesser charge of culpably causing death. The judgement of common opinion is even more hesitant when Dr Arthur's action is considered simply in terms of morality and without reference to the law. As the situation presented itself at the relevant time, this was a straightforward case of a baby born with Down's syndrome. There was no reason to think that the baby needed anything more than normal care and nurture. But the parents, overcome by the natural shock and distress of learning that the child had Down's syndrome, did not want it to survive, and Dr Arthur was prepared to go along with them. The evidence given at his trial indicated that many, but not all, paediatricians would have acted in the same way. He was following a fairly well established practice and so he was not faced with a genuine dilemma, though he may have felt a dilemma on the first occasion when he had to make such a decision. To many members of the general public, who were unaware of paediatric practice, the case of the Pearson baby did appear to present a painful dilemma.

Strictly speaking, it was a trilemma. For if the baby's life was to be preserved, it did not follow that the burden of looking after him should necessarily fall upon the parents. It could be shouldered by an agency of the general community. If we are honest with ourselves, the main argument for allowing a Down's syndrome baby to die is not that his life will be too much of a burden to him but that it will be too much of a burden to his immediate family; and if we judge that the child's right to life outweighs the burden to others of looking after him, there is very little reason to say that his right implies a burdensome duty for his parents and siblings rather than a duty for the community as a whole. Once you look at the situation in that way, however, you then need to ask why the decision of life or death should be left to the parents and the doctors. 
This aspect of the problem was highlighted by the second case which came before the courts, in July 1981, a year after the Pearson baby had been born and left to die, but some months before the trial of $\mathrm{Dr}$ Arthur. It is the case of In re B (A Minor), [1981] $1 \mathrm{~W}$ L R 1421, C A. A baby girl named Alexandra was born on 28 July 1981 suffering from Down's syndrome and from an intestinal blockage which would have been fatal within a few days if not removed. The parents of the child decided to refuse consent to the operation because the child would in any event have the defects of Down's syndrome. In this case, unlike that of John Pearson, it was plain that the parents reached their decision after careful deliberation and sincerely believed that they were acting in the best interests of the child. The doctors, disagreeing with the view of the parents, contacted the local authority, which made the child a ward of court and applied for care and control and for an order authorising the operation. The intention was that future care of the child would, if necessary, be handed over to foster parents, which is in fact what happened in the end.

In the case of Alexandra, the judge at first agreed to the request of the local authority. But when the child was transferred to another hospital in order to undergo the operation, and when the surgeon there refused to operate because the parents had not consented, the issue came back to court with the parents present, and this time the judge refused the application of the local authority. At the Court of Appeal, however, both of the judges who heard the case decided in favour of the local authority. It was stated in evidence that if the operation were performed successfully, the child would have a life expectancy of 20 to 30 years, but the quality of her life could not be predicted at present.

Lord Justice Templeman said the crucial issue was 'the interests of the child'; the court had to decide whether the child's life was 'demonstrably going to be so awful' that she 'must be condemned to die', or whether such a 'condemnation' would be wrong because the quality of her life was 'imponderable'. The judge in the lower court had erred in concluding that the wishes of the parents ought to be respected; the decision ought instead to depend on the interests of the child.

I always find it difficult to interpret the idea that death can be the interest or the best interest of someone. Since death will terminate his or her existence, how can one speak of there being any interest, positive or negative, arising from death? You can certainly say that in some circumstances the misery of a human life can be judged to outweigh its happiness, actual or potential. You can also say that a human being, if capable of exercising choice, may prefer to die rather than to continue living in those (or other) circumstances. At any rate this is the only way in which I can make sense of the statement that it may be in the interests of a person to allow him to die.

My interpretation fits in with the way in which the judges of the Court of Appeal in the case of baby
Alexandra elaborated their reference to the interests of the child. Lord Justice Templeman asked 'whether the life of this child is demonstrably going to be so awful that in effect the child must be condemned to die', and he contemplated the possibility of such a conclusion when the life of a child was 'bound to be full of pain and suffering'. Lord Justice Dunn said 'there is no evidence that this child's short life is likely to be an intolerable one'. Lord Justice Templeman's remarks suggest that a more weighty criterion is required than a mere balance of pain over pleasure, and for that reason it is not strictly utilitarian, but it does indicate that the scale can be tipped by a great preponderance of pain. Lord Justice Dunn's reference to an 'intolerable' life may be understood similarly or may be taken to refer to choice, what the person concerned is prepared to accept as tolerable. Of course the criterion of choice or preference does not apply at the time to a recently born infant, but the judge was speaking of the life expectancy of 20 to 30 years and may have had in mind Alexandra's probable thoughts and feelings about preference when she came to maturity. The relevant evidence for such contemplation is the experience at maturity of other persons with a similar handicap. Judging from what $I$ have read and from a discussion of senior nurses which I have heard, my understanding is that almost all persons with such a handicap say, if asked, that they regard their lives as being happy overall and that they would not prefer to have been allowed to die at birth. A judgement to the contrary of this has been expressed by a very small number of people with handicaps much more serious than Down's syndrome, and this needs to be borne in mind when considering what is the right thing to do with a very severely handicapped neonate. So far as baby Alexandra was concerned, Lord Justice Dunn was surely right to conclude that 'the child should be put in the same position as any other mongol child'.

I have quoted extracts from the Court of Appeal judgements in Alexandra's case which reflect a consequentialist outlook: 'whether the life of this child is demonstrably going to be so awful that in effect the child must be condemned to die'; 'there is no evidence that this child's short life is likely to be an intolerable $\tilde{N}$ one'. These words seem to imply, and Lord Justice N Templeman went on to say, that a court might be presented with evidence that the life of a newly-born child would, if preserved, be 'demonstrably so awful' that the court might then 'condemn' the child to die. Should we take this implication at its face value? $\mathrm{Mr}$ Larry Gostin, the then Legal Director of the organisation MIND, wrote in a letter to The Times 16 September 1981:

'It should be observed that the courts have never upheld the decision of a parent to withhold consent for a needed medical treatment. The judiciary has consistently upheld the principle in a variety of contexts that a parent cannot make decisions against the best interests of the child. 
'It may be that there is evidence that a child's life would be so demonstrably awful, due to prolonged suffering, that it would be in the best interests to die. However, it is very difficult to envisage the circumstances in which a court would decide, in the absence of any indication of parliamentary intent, that some children's lives were not worth living.'

If this is a correct understanding of the spirit of case law on the subject, then the suggestions of a consequentialist outlook in the judgements of In re $B$, and even the time-honoured expression 'in the best interests of the child', are misleading. The real underlying criterion is respect for the sanctity of human life. That inference is supported by the hesitancy with which Lord Justice Templeman said that a court 'might' rather than 'would' be driven to a different conclusion.

The inference receives some support also from a Court of Appeal judgement of 1982 (McKay v Essex Area Health Authority [1982] QB 1166, CA). This case concerned a claim that a child who was born deformed had a right not to have been born, and that the hospital authorities had been negligent in failing to advise abortion. The court decided that the claim was misconceived, and in the course of delivering the principal judgement, Lord Justice Stephenson referred to the provision in the Abortion Act of 1967 which permits abortion when there is a substantial risk that the child would be seriously handicapped. He said that the legislature had thereby made 'a notable inroad on the sanctity of human life'. By reason of the Abortion Act, the judge continued, a doctor could owe a duty to the mother to advise her of her right to have an abortion, but he had no comparable duty to the child.

'To impose such a duty towards the child would, in my opinion, make a further inroad on the sanctity of human life which would be contrary to public policy. It would mean regarding the life of a handicapped child as not only less valuable than the life of a normal child but so much less valuable that it was not worth preserving.'

There are two features in this judgement which deserve particular notice. One is the anomaly introduced by the Abortion Act of 1967. It happens to be highlighted in the case of Alexandra because the mother of Alexandra had undergone an amniocentesis test during pregnancy and would have had an abortion if the test had indicated Down's syndrome. The mother was in her late thirties and had taken the test because the incidence of Down's syndrome tends to rise with a rise in the age of the mother. In this particular instance the test was repeated six times but failed to produce a positive result. One can understand that the shock and disappointment of giving birth to a Down's syndrome baby would be all the greater for coming after the negative result of the amniocentesis test. The parents were then confronted with the anomaly that we have one law for abnormal fetuses and another law for abnormal neonates. It may well be that the existence of the Abortion Act of 1967 has made doctors rather more ready than before to go along with parents who reject a handicapped baby, or even in some cases to suggest to them the option of rejection (2). Of course the anomaly can be used to argue either that the law should be relaxed in respect of newly-born babies or that it should be tightened for abortion.

As so often in areas of biology, there is a continuum of development so that the drawing of a firm line at one particular point seems arbitrary. Nevertheless, lines do have to be drawn for legal and other practical purposes (for example, for the age of majority or the age of consent), and the law has traditionally found it convenient to draw a line at the time of birth for distinguishing between abortion and infanticide as offences of lesser and greater gravity. In the light of that tradition, the difference in the present law with regard to defective fetuses and defective newly-borns is less anomalous than appears at first sight.

The second noteworthy feature about Lord Justice Stephenson's judgement is that Common Law, in the absence of statutory direction, resists the idea that the life of a severely handicapped child is not worth preserving. The types of handicap that are commonly brought into medical ethics discussions about neonates range from Down's syndrome, through spina bifida, to anencephaly, a condition in which the child has little or no brain. Very few people, even among those who follow traditional Roman Catholic doctrine, would advocate that doctors should take special measures to preserve the lives of anencephalic babies. Does not this indicate a judgement that such a life is 'not worth preserving'? Perhaps it should not be classified as a properly human life. A child with little or no brain presumably can have no consciousness, and that would be adequate reason for judging that its life should not be counted as a human life. Whichever way we look at it, one can hardly imagine that a court would insist upon the preservation of such a life for as long as possible. It is equally hard to imagine that anyone would challenge in the courts a decision by doctors to allow an anencephalic baby to die (3).

But of course there is a considerable range of possible disabilities between anencephaly on the one side and Down's syndrome (with or without some relatively simple complication) on the other. Many of them present a moral dilemma, and different people will be inclined to come down on different sides of the fence. The resolving of medical disagreement has to be left to doctors in the light of their experience of the results of treatment. The decisions which are reached for particular cases, however, rarely depend on medical considerations alone. Predicting the kind of life that a handicapped child will have is a medical matter; judging whether that life will be a worthwhile human life is an ethical matter. Trying to give honest guidance to parents is a function of the doctor; judging whether the views of parents should be decisive is not. 
For that matter, judging whether the views of doctors should be decisive is also not a function of doctors, as they recognise when they advise the parents.

Professor Ian Kennedy, in his Reith Lectures of 1980 , argued that the decision should not be left to doctors because the issues of medical ethics depend essentially on moral judgement and not on medical expertise. He evidently thought that the law should have a role but was understandably vague about the nature of that role. Clearly it would not do to bring every disputed case before a court. There is not the slightest reason to think that a judge is in a better position to decide on an individual case than the doctor and the parents who have been close to it. What a judge can do is to interpret general guidelines that have been set out in legislation or in case law.

Most doctors do not welcome the intervention of the law in their difficult cases. They think, reasonably enough, that the best way to meet these harrowing situations is to rely on the sensitive awareness by the doctor of the whole web of intimately connected circumstances - the medical possibilities and prognosis, the nature and weight of the burden of care to be shouldered by the parents, the effect on sibling children, and the way in which individual parents are likely to face these problems. Yet this way of looking at things can mean a preoccupation with consequences that blurs respect for the rights of the child. That phrase 'the rights of the child' is perhaps inadequate. Rights are ascribed to the child as a person or potential person. What is blurred is the moral respect owed to a person. If the doctors and the relatives were considering an issue of life or death for an adult who was compos mentis, the cardinal consideration would be the choice of the patient himself. An infant cannot choose, and the infants who are afflicted with very severe disablement of the brain will never be able to choose; but many of those with Down's syndrome or spina bifida will be capable of expressing a retrospective choice, if their lives are preserved. Does this enter into the factors which doctors weigh up when advising the parents? Ought it not to do so? Is this a moral factor that outsiders may be better seized of? It will seem remote to doctors and parents, who are deeply exercised by immediately manifest difficulties.

It can properly be treated as remote if the problem really is one of judging what is in the best interests of the child - if, for example, it is a question of an operation to sacrifice an organ or a limb in order to prevent some other disability. But when the issue is one of life or death, there are no interests of the patient to be calculated in the event of death. Nor does the decision turn on calculating the interests of the patient if his life is preserved, that is to say, on weighing his probable happiness against his probable misery. The decision in fact turns on weighing the interest of others, in terms of the burden they will have to bear, against the natural or human right to life which is ascribed to the patient. An aspect of the second constituent is recognised by medical tradition in the primary duty to save life. Yet the prevalent practice of $\frac{\text { W }}{\mp}$ paediatricians suggests that they tend to think it is easily outweighed by the first constituent, the burden of care (which, they assume, must be borne by the child's family rather than by the community as a 0 whole); and it seems to me that their perspective on this 음 matter differs markedly from that of the Common Law and has run ahead of the perplexity experienced by the $\mathbb{\widetilde { D }}$ average citizen.

In a BBC Radio 3 discussion between Professor Ian क Kennedy and an Australian judge, Justice Michael. Kirby, broadcast on 7 February 1984, the judge observed that issues of life and death have traditionally come within the purview of the law. Whatever may be thought about the plethora of rights claimed in recent times to be fundamental human rights, the right to life $\vec{P}$ is undoubtedly basic, calling for the protection of the law.

So far as handicapped infants are concerned, there have been suggestions both for legislation and for local $\vec{z}$ ethics committees. I am inclined to think that there is a need for legislation in order to set firmer guidelines $\stackrel{\rho}{\supset}$ for doctors and judges alike. At present there is a wide discrepancy between the principles of the Common Law enunciated by senior judges and the principles accepted by senior paediatricians. Lord Justice Templeman in the case of $I n$ re $B$ and Lord Justice Stephenson in the case of $M c K a y$ were both hesitant to concede that a court would say it was lawful to allow a handicapped infant to die if its handicap was extremely severe. This may be because they did not know just how awful these handicaps can be and how far modern medicine can nevertheless stave off a natural death. At any rate they were reflecting the spirit of the Common Law as it has developed in an era of less sophisticated medical technology. On the other side, the judgement in the case of In re B undoubtedly contradicts the view that Down's syndrome alone makes life not worth living. Yet at the trial of $\mathrm{Dr}$ Arthur several distinguished doctors were prepared to support his course of action; one of them, Sir Douglas Black, then President of the Royal College of Physicians, went so far as to declare: 'I say it is ethical that a child suffering from Down's syndrome . . . should not survive' (4). In o such an open conflict between Common Law and medical opinion, it is surely desirable for Parliament to enact a statutory principle.

After the trial of Dr Arthur at least two suggestions for a parliamentary Bill were proposed for consideration. One was drafted by Diana and Malcolm Brahams; the other was drafted on behalf of Prospect, a group of parents of severely handicapped children, who supported Dr Arthur (5). Both draft Bills propose that it should be lawful to limit the medical treatment of an infant under twenty-eight days old, provided that the parents consent and provided that two experienced doctors certify that the child is suffering from a severe physical or mental disability which is irreversible, or which no treatment would (significantly) alleviate, 'or which is of such gravity ... that the patient would 
enjoy no worthwhile quality of life'. Observe that the wording, in both draft Bills, describes alternatives: the disability must be irreversible, or incapable of (significant) alleviation, or of a gravity that makes the quality of life unworthwhile. I doubt very much indeed whether Parliament or the public would accept a Bill which made an unworthwhile quality of life a possible but not a necessary condition of letting the baby die. The use of 'or' in the Brahams' draft Bill is clearly not an error for 'and', and the use of the word in the description of the Prospect draft Bill given by Mrs Catherine Gillespie (in a letter to this journal) is unlikely to have been an error since she said that the members of Prospect supported Dr Arthur (6). If a statute were to require unworthwhile quality of life as a necessary condition of limiting treatment, it would surely not cover Dr Arthur's initial diagnosis of the Pearson baby as a simple case of Down's syndrome with no complications. Certainly the Appeal Court judgements in the case of In re $B$ imply that the life of a child with uncomplicated Down's syndrome can be worthwhile. Presumably the supporters of the draft Bills would want to limit treatment for such cases by means of the other provisions of their Bills concerning irreversible and unalleviable disability.

If the wording of the draft Bill were amended so as to make all three provisions necessary conditions, the proposal might well be acceptable to Parliament and public. The phrase 'no worthwhile quality of life' is too vague as it stands, and in the Brahams' draft Bill the doctors who reach the decision on quality of life are required to take account of several detailed considerations. Commenting on their proposal, Dr John Havard, the Secretary of the British Medical Association, has expressed serious misgivings about the inhibiting effect of such detailed provisions in a statute (7). He has also properly criticised the unsuitability of the adversarial procedure of British criminal law for dealing with situations like that faced by $\mathrm{Dr}$ Arthur. However, it should not be beyond the wit of man to suggest an alternative form of words to 'worthwhile quality of life' without having to go into great detail of interpretation; and while there might be occasional recourse to the courts on the question of interpretation, it should certainly not be necessary to bring criminal charges, as was done in the case of $\mathrm{Dr}$ Arthur. What is required, in my opinion, is a statutory statement of principle in order to remove the gap that now exists between the principles of Common Law, as stated by the Court of Appeal, and the principles apparently accepted by a number of leading medical practitioners. The main purpose of this paper has been to draw attention to that gap.

D D Raphael is Emeritus Professor of Philosophy, London University and Senior Research Fellow, Department of Humanities, Imperial College of Science and Technology, London SW7.

\section{References and notes}

(1) This is a shortened version of the Austin Lecture delivered to the Association of Legal and Social Philosophy in 1986. A complete version, under the title Life and death: medical ethics and the law, has been published in the Archiv für rechts- und sozialphilosophie, Beiheft 32 (1987).

(2) A BBC Panorama programme in 1981 included an interview with the mother of a Down's syndrome baby. She recounted a suggestion of this kind made to her by a paediatrician. Reported in an article by Annabel Ferriman in The Times, 1981 Nov 9.

(3) At the trial of Dr Arthur in 1981, one witness, Dr Peter Dunn, spoke of a paediatrician in the United States who feared 'the retribution of the law' if he allowed an anencephalic baby to die. Such anxieties were presumably dispelled by a decision of the US Supreme Court, in December 1983, to reject a 'right-to-life' challenge in the case of 'Baby Jane Doe', whose condition was less severe than anencephaly.

(4) Quoted from Kuhse H, Singer P. Should the baby live? Oxford: Oxford University Press, 1985: 8.

(5) The Bill drafted by the Brahams, together with a discussion by the authors, was printed in the fournal of medical ethics 1983; 9: 12-15, after having been previously published in The Law Society's gazette. The Bill drafted on behalf of Prospect was described in general terms by Catherine Gillespie in a letter published in the fournal of medical ethics 1983; 9: 231; it does not differ from the general provisions of the Brahams' draft but it may perhaps have dropped some of the particular provisions of the earlier draft which gave rise to criticism.

(6) In recent correspondence with the editor of this journal and with myself, Mrs Gillespie has wavered between the two words. She has appreciated my point that 'or' would be unacceptable to Parliament and public, but she has also recognised the force of my argument that an Act containing the word 'and' would not have protected Dr Arthur.

(7) Havard J. Legislation is likely to create more difficulties than it resolves. Fournal of medical ethics 1983; 9: 18-20. 